\title{
DE NUEVO EN TORNO AL PROTOCEJEL DEL AÑO 913
}

F. CORRIENTE

Universidad de Zaragoza

Hace ya algunos años señalamos la existencia en el volumen $\mathrm{V}$ de Almuqtabis de Ibn Hayyān de una peregrina noticia acerca de un acemilero de las tropas de 'Abdarraḩmān III, en campaña contra Ibn Hafsūn para arrebatarle la fortaleza de Juviles ', el cual habría sido promovido a rango militar por su socorrida respuesta congruente a una invectiva lanzada contra el aún muy joven soberano por uno de los defensores de aquella fortaleza. Noticia que es peregrina no sólo por el hecho en sí, sino también por ir acompañada de ambos textos en dialecto andalusí, invectiva y respuesta, lo que constituye uno de los más antiguos especímenes de su género y, en términos absolutos, la más antigua documentación de un texto poético no clásico procedente de Alandalús.

Ya en aquel momento pusimos de relieve ese carácter especialísimo, así como el hecho de que la métrica subyacente a esta composición era idéntica a la que utiliza la poesía estrófica andalusí, tanto clásica (muwašsah̆), como dialectal (cejel), o sea, según nuestra teoría, una adaptación del carū d clásico a la peculiar recitación del árabe, clásico o dialectal, en un medio lingüístico donde se había perdido el ritmo cuantitativo, sustituyéndolo, por interferencia del sustrato hispánico, por el acentual.

Como quiera que el dato parecía no llamar demasiado la atención, quizás por ir incluido en una obra utilizada fundamentalmente por historiadores del Islam y no por especialistas en literatura árabe o andalusí, volvimos sobre ello en la ponencia presentada en el Coloquio de Exeter sobre xarajāt ${ }^{2}$, cuyas actas sufrieron cierto

' V. Crónica del califa 'Abdarrahmān III An-Nasir entre los años 912 y 942 (alMuqtabis V), trad., notas e índices por M.` J. Viguera y F. Corriente, Zaragoza 1981. El carácter poético del texto no había sido aún detectado en la edición árabe, Ibn Hayyan, Almuqtabis (aljuz' alxamis), ed. P. Chalmeta y F. CorRiente, Madrid 1979, pág. 64.

${ }^{2}$ Celebrado en dicha ciudad en enero de 1988. 
retraso en ser publicadas y, por ello y nuevamente, en el Primer Congreso Internacional sobre Poesía Estrófica árabe, Hebrea y paralelos romances ${ }^{3}$, cuyas actas también acaban de aparecer.

Pero el asunto, como casi todas las cuestiones de auténtica importancia en la investigación científica, distaba aún mucho de estar cerrado y agotado, aun cuando la mala fortuna de las publicaciones en que hubiera debido salir antes a la luz hubiese diferido su más amplio conocimiento por los círculos interesados. En una nueva reciente conversación con nuestro querido amigo y respetado maestro, el Dr. Mahmud Ali Makki, éste puso en mi conocimiento la existencia de una versión paralela del mismo suceso y texto en la obra de Ibn Simāk, editada por él, Azzaharāt almantūura ${ }^{4}$. Al consultar dicha versión, pudimos apreciar algunas diferencias textuales que no afectan básicamente a las conclusiones que en su momento habíamos derivado acerca de las importantes implicaciones de este testimonio para el mejor conocimiento de la génesis de la poesía estrófica andalusí y su especial versión del carū dirección, así como permiten establecer con más seguridad un texto primitivo, totalmente merecedor de tal mejora editorial: con motivo del homenaje que tributamos a nuestro compañero y maestro, Dr. D. Fernando Díaz Esteban, uno de cuyos campos de investigación ha sido el de la poesía estrófica de este tipo, especialmente en su vertiente hebrea, nos ha parecido éste lugar adecuado para exponer los nuevos datos y hacer los oportunos ajustes de interpretación.

El texto inserto en Almuqtabis $V$ a renglón corrido y sin reflejar ni reconocer en él estructura métrica alguna, quedaba así, según nuestra primera interpretación:

\section{/rúddu rúddu+bn+úmmu fi fúmmu wálla la narúddaha illa rás aban hafșúni fi húkmu s/}

que medía como madtd, sin más manipulaciones que suprimir un /bi-/ antes de /rás/ y dar a / hafşūn/ una vocal de $i$ crāb, condenada en la preceptiva del prólogo de Ibn Quzmān, pero muy a menudo utilizada por los cejeleros para salir de apuros y obtener una de las excesivamente escasas sílabas breves necesarias para la aplicación del carūd, aún en

${ }^{3}$ Celebrado en Madrid en diciembre de 1989.

4 Ibn Simāk Al'āmili, Azzaharăt almantūra ft nukat al'axbār alma'tūra, ed. M. 'A. Makkî, Madrid 1984, pág. 95.

${ }^{5}$ V. Crónica, pág. 59, $\mathrm{n}^{\mathrm{Q}} 18$. 
su versión adaptada. Con este texto traducíamos: «Rechazad, rechazad al hijo de su madre (dándole) en la boca", invectiva del sitiado a la que habría replicado el acemilero: «Pardiez que no nos tornaremos (de la campaña) sino con la cabeza de Ibn Hafșūn en su poder».

El texto de Azzaharāt almantūura presenta algunas variantes: /rúddu/ no se repite y, en lugar de $>>b n<$ tiene $>$ lbn $<$. De ellas, la primera variante no tiene gran importancia, puesto que se podría interpretar como mera desaparición haplológica; en cambio la segunda, mucho mejor para el sentido que la variante de Almuqtabis $V$, no sólo obliga a reinterpretar ese verso, sino que impide su escansión como madîd y replantea la legitimidad, sintácticamente siempre dudosa, de la supresión de /bi-/ en el tercer verso.

Ello nos ha obligado a pensar y reestructurar este texto de forma que, manteniendo el principio de que es verso, como indican la rima y las circunstancias del suceso ${ }^{6}$, se le pueda nuevamente atribuir una forma métrica en los segmentos pertinentes y explicar su ausencia en aquéllos donde no lo es. De esta reflexión han salido las consecuencias siguientes:

1) /rúddu/, sencillo o repetido, no es segmento poético sino fórmula de citación, con la que se introducía la invectiva, ésta ya sí segmento poético. El valor formulaico de tal expresión puede ser importante, ya que no resulta aventurado suponer que se trataba de un género, cuyos antecedentes en la poesía belicosa de los árabes son bien conocidos, que tal vez se llamaba así (/rúddu rúddu/ o /rád/), practicado en las fases previas a encuentros armados.

2) Nuestro supuesto segundo verso no es tal, sino también fórmula introductoria de la contrainvectiva, con que se respondía a la invectiva, como se desprende del hecho de que estas palabras no puedan en modo alguno tener la misma ni parecida estructura métrica que lo que la precede o sigue.

3) Los antiguos versos 1 y 3 siguen siendo tales, aunque escandibles ahora según el metro mustafil (mafa`tlun facülun): /labán úmmu fi fúmmu/ y /rás ban hafşún fi húkmu/?

${ }^{6}$ Es impensable que una mera réplica en prosa hubiese producido tan favorable impresión en el ánimo del soberano como para otorgar ascenso tan espectacular.

7 Acerca de este metro, uno de los abhur muhmala citados por Ibn Bassām en su famoso texto de la Daxtra acerca del muwassah con expresión no entendida por muchos, v. Poesía estrofica (cejeles y/o muwašsahăt) atribuida al mistico granadino Ašsustart (siglo XIII d. C.), Madrid 1988, pág. 6. La supresión de la alif de >’bn< no 
La versión castellana queda, pues, así:

Responded (, responded):

- "La leche de la madre (aún lleva) en la boca".

No responderé a eso sino con:

- “(Y) en su poder la cabeza de Ibn Hafșūn”.

Esta modificación del texto editado y su interpretación métrica podría despertar sospechas acerca de la seriedad de la metodología utilizada y la solidez de las conclusiones derivadas del documento. No debe de ser así, ya que es irrebatible la presencia en él de segmentos poéticos y que, siendo un fragmento tan breve y no sin algunas dificultades de transmisión, es obvio que la aparición de un texto paralelo con algunas variantes que alteran la secuencia silábica necesariamente conlleva una modificación del esquema métrico propuesto en principio: lo mismo nos ocurriría con cualquier breve texto poético árabe clásico del que apareciera otra versión, sintácticamente más correcta, pero con secuencia silábica alterada.

Por lo demás, este texto al que seguiremos llamando protocejel porque aún no tiene, o su brevedad no le permite, exhibir estructura estrófica, pero ya en dialecto andalusí y en carü este último sentido, un perfecto predecesor del cejel típico, al hacer, por ejemplo, en el segundo verso una sustitución de mafácîlun por fấilātun y por hacer funcionar la átona ban como breve, licencias consustanciales con la adaptación del carū d al ritmo acentual ${ }^{8}$.

Seguimos, pues, opinando y estando fundamentados para hacerlo, que el más antiguo espécimen de poesía no clásica en Alandalús está en andalusí y no en romance, unos dos siglos antes de las

puede considerarse manipulación notable, puesto que no sólo es habitualísima en la lengua del cejel sino que, incluso en documentos en lengua clásica, su eliminación o adición en consonancia o violación de las reglas ortográficas que le son propias depende a menudo de la opinión del copista.

${ }^{8}$ Dichas licencias son: 1.") Utilización en el interior del verso de alteraciones de pies solamente permitidas en el último en la métrica xaliliana. 2.") Sustitución, sobre todo en los pies no finales de verso, de cualquier pie por otro de idéntico número de silabas. 3.") Abuso de la sustitución de hamz por wasl y viceversa. 4.") Eventual cómputo como breve de sílabas terminadas en vocal larga o diptongo. 5.") Eventual cómputo como breve de sílabas $\mathrm{KvK}$, a condición de ser átonas. 6.") Prefijación, sufijación o infijación de grupos de sílabas, una o dos, rara vez tres, anceps generalmente salvo el caso de la sufijación, ya que la porción final de estos poemas era la menos alterable para salvaguardar al menos parte de su ritmo propio. 
primeras xarajāt y utilizando ya la adaptación acentual del carūd que luego se haría típica de las muwaššahāt más castizas y del cejel, antes de su reabsorción por la preceptiva clásica. Creemos que ya no es necesario insistir en que aquella métrica en ninguna forma puede ser de origen autóctono, aunque sí lo es la circunstancia que determina su evolución, o sea, la sustitución del ritmo entonacional, pero además, este testimonio sigue añadiendo una considerable dificultad a la teoría que ve en la xarja un mero resto de una poesía romance preexistente: sin negar que ello pueda ser así ocasionalmente, resulta evidente su falta de peso específico frente a la mayoría de las xarajāt en andalusí y a la posibilidad de que las romances sean traducidas, adaptadas o, seguramente, manipuladas para hacerlas entrar en un poema árabe, cuya métrica nunca fue sino un arreglo de la xaliliana.

\section{RESUMEN}

Este singular texto, extraído de Almuqtabis de Ibn Hayyān, es ahora revisado y editado a la luz de la versión paralela incluida en Azzaharāt almantūra ft nukat al'axbār alma'tūra de Ibn Simāk Al'Āmilì, obra recientemente publicada por el Dr. M. A. Makkî. Las necesarias correcciones producen un texto más castizo, que requiere una escansión diferente, pero continúa apoyando los principios establecidos por el autor para la versión acentual del carū generada en Alandalús y que constituye la base métrica del muwašsah y cejel, como consecuencia de la pérdida del ritmo cuantitativo en la pronunciación local del árabe.

\section{SUMMARY}

This unique text excerpted from Ibn Hayyān's Almuqtabis is now revised and reedited in the light of a parallel version included in Ibn Simāk Al'Āmilî̉s Azzaharāt almantūra fl nukat al'axbār alma'tūra recently published by Dr. M. A. Makkī. The necessary emendations bring forth a better idiomatic wording, while requiring a different scansion, but yet upholding the principles laid down by the author for the stress-based version of 'arū devised in Alandalus and most conspicuously underlying the metrics of muwašah and zajal as a consequence of the loss of quantitative rhythm in the local pronunciation of Arabic. 